\title{
SPECIFIC FEATURES OF THE OXYFUEL COMBUSTION CONDITIONS IN A BUBBLING FLUIDIZED BED
}

\author{
Pavel SkopeC*, Jan HrdličKa \\ CTU in Prague, Faculty of Mechanical Engineering, Department of Energy Engineering, Technicka 4, 16607 \\ Prague, Czech Republic \\ * corresponding author: p.skopec@fs.cvut.cz
}

\begin{abstract}
Oxyfuel combustion is a promising approach for capturing $\mathrm{CO}_{2}$ from power plants. This technology produces a flue gas with a high concentration of $\mathrm{CO}_{2}$. Our paper presents a verification of the oxyfuel combustion conditions in a bubbling fluidized bed combustor. It presents a theoretical analysis of oxyfuel combustion and makes a comparison with combustion using air. It is important to establish a proper methodology for stoichiometric calculations and for computing the basic characteristic fluidization properties. The methodology presented here has been developed for general purposes, and can be applied to calculations for combustion with air and with oxygen-enriched air, and also for full oxyfuel conditions. With this methodology, we can include any water vapour condensation during recirculation of the flue gas when dry flue gas recirculation is used. The paper contains calculations for a lignite coal, which is taken as a reference fuel for future research and for the experiments.
\end{abstract}

KEYworDs: oxyfuel combustion; bubbling fluidized bed; flue gas recirculation.

\section{INTRODUCTION}

Energy production from the combustion of fossil fuels is accompanied by the formation of harmful emissions. For several decades, there have been discussions about climate change caused by the production of greenhouse gases, and efforts are being made to reduce their production as much as possible. CCS technologies (Carbon Capture and Storage, or Carbon Capture and Sequestration) are one of the main approaches to the reduction of carbon dioxide emissions from stationary energy sources. Several technological options are under investigation, including oxyfuel combustion. Oxyfuel combustion uses oxygen as an oxidant with a high degree of flue gas recirculation. This increases the $\mathrm{CO}_{2}$ concentration in the flue gas by eliminating molecular nitrogen from the combustion air. It is then easier to remove the remaining minor components from the $\mathrm{CO}_{2}$-rich flue gas. The maximum $\mathrm{CO}_{2}$ concentration in the flue gas during air combustion is not higher than $20 \%$, but oxyfuel combustion can increase this concentration up to $90 \%$ in the dry state. Another benefit of oxyfuel combustion is that it reduces the emissions of other pollutants and increases the combustion efficiency [1].

The basic design of oxyfuel combustion technology has been known since 1982. The technology that was developed at that time provided a rich $\mathrm{CO}_{2}$ gas for enhanced oil recovery. During the 1990s, oxyfuel combustion was initiated as a CCS technology. Current research focuses on pulverized coal combustion, and there is also interest in circulated fluidized bed combustion. Several laboratory and pilot experimental facilities focusing on a circulating fluidized bed and pulverized coal combustion have been set up worldwide [1, 2]. The Schwarze Pumpe pilot power plant in Germany 3 is a major project. It has power output of about $30 \mathrm{MW}_{\mathrm{th}}$ (though it has not been in operation recently). The Callide Power Station in Australia [4] is the facility with the highest power output until now, with an electric power output of $30 \mathrm{MW}$. Major facilities, with $30 \mathrm{MW}_{\text {th }}$ pulverized coal and $30 \mathrm{MW}_{\text {th }}$ circulating fluidized bed boilers, are under investigation by CUIDEN in Spain [5]. A $3 \mathrm{MW}_{\mathrm{th}}$ full chain system has been constructed in China, and a $35 \mathrm{MW}_{\text {th }}$ unit is ready for commissioning. In addition, some commercial-scale oxyfuel power plants are currently under preparation: a $200 \mathrm{MW}_{\mathrm{e}}$ facility, by the Shenhua Group in China, and a $426 \mathrm{MW}_{\mathrm{e}}$ facility by Whiterose in the UK [6]. Other important projects are flexiburn facilities, which are able to operate under oxy-combustion and air combustion mode. They have been proposed by Foster Wheeler and by researchers from the Czestochowa University of Technology [7]. A few investigations have been made in the field of bubbling fluidized bed combustion (BFBC), which is more suitable for lower power capacities. Only a few published results are available on BFBC.

Our paper reports on a theoretical analysis of oxyfuel combustion, and contains a comparison with combustion using air. A suitable methodology is proposed for stoichiometric calculations and for computations of basic characteristic fluidization properties. The methodology presented here has been developed for general purposes, and can be applied to calculations for combustion using air, using oxygen-enriched air, and also for full oxyfuel conditions. 


\begin{tabular}{llllll}
\hline & $\omega_{\mathrm{O}_{2}}$ & $\omega_{\mathrm{CO}_{2}}$ & \multicolumn{1}{c}{$\omega_{\mathrm{N}_{2}}$} & \multicolumn{1}{c}{$\omega_{\mathrm{Ar}}$} & $\omega_{\mathrm{H}_{2} \mathrm{O}}$ \\
\hline Air & 0.2062 & 0.0004 & 0.7685 & 0.0092 & 0.0157 \\
Oxygen 1 & 1 & 0 & 0 & 0 & 0 \\
Oxygen 2 & 0.95 & 0 & 0.05 & 0 & 0 \\
Air+oxy 30 & 0.3 & 0.0003 & 0.6777 & 0.0081 & 0.0139 \\
Air+oxy 50 & 0.5 & 0.0002 & 0.4841 & 0.0058 & 0.0099 \\
\hline
\end{tabular}

TABLE 1. Volume concentration of the substances in different types of oxidant.

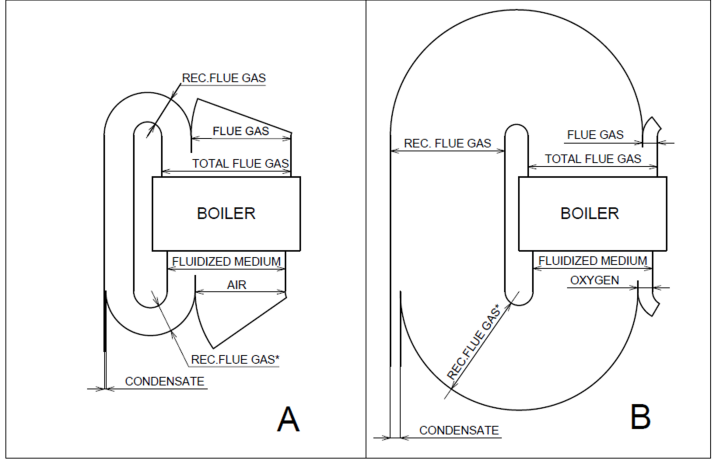

FIGURE 1. A comparison of the volume flow of all streams of gases for combustion with air (A) and with oxygen (B).

\section{Characteristics of OXYFuel COMBUSTION}

Conventional combustion technology uses air as an oxidant for combustion. Air contains $79 \%$ nitrogen, which is therefore the main component of the flue gas. This means that there is a low $\mathrm{CO}_{2}$ low concentration, and the available separation methods (e.g. the amine method) are relatively complicated and expensive. Oxyfuel combustion uses a mix of oxygen (usually with economical purity of $95 \%$ ) and recirculated flue gas. The flue gases are formed mainly by a mixture of water vapour and $\mathrm{CO}_{2}$. The water vapour is easily removed by condensation, and only minor components need to be removed from the $\mathrm{CO}_{2}$.

Oxyfuel combustion and air combustion use different volumes of all streams of gases (Fig. 1). All streams are displayed in the real scale of real flows (normal cubic meters).

The flue gas recirculation stream for oxyfuel combustion is shown in Fig. 1. Part B is set up to ensure the same volume of fluidization medium as there would be for combustion using air.

There are two reasons for recirculating the flue gas:

- It replaces the volume of nitrogen particularly by $\mathrm{CO}_{2}$, and thus provides a sufficient amount of heat carrier.

- In the case of fluidized bed boilers, it provides a sufficient volume of fluidization medium.

Flue gases from oxyfuel combustion consist mainly of $\mathrm{CO}_{2}$ and water vapour (Fig. 2). This has different physical characteristics from those of the flue gases from air combustion, which consist mainly of $\mathrm{N}_{2}$. The main differences during oxyfuel combustion are:

- In order to reach the same adiabatic flame temperature, it is necessary to reduce the oxygen concentration in the fluidization medium to below $30 \%$. More than $60 \%$ of the total flue gas from the boiler needs to be recirculated.

- The high concentration of $\mathrm{CO}_{2}$ and water vapour causes higher emissivity of the gas, which leads to greater radiation heat exchange.

- The density of the flue gas is higher due to the higher molar mass of $\mathrm{CO}_{2}(44 \mathrm{~g} / \mathrm{mol})$ in comparison with $\mathrm{N}_{2}(28 \mathrm{~g} / \mathrm{mol})$.

- The molar $\mathrm{CO}_{2}$ heat capacity is 1.25 times higher than that of $\mathrm{N}_{2}$ because of its larger molecular weight [8]. The flue gas heat capacity from oxycombustion is about one quarter higher than the flue gas heat capacity from air combustion, taking into account wet flue gas recirculation and an $\mathrm{O}_{2} / \mathrm{CO}_{2}$ ratio of $30 / 70$.

- The excess of air during air combustion is usually around $20 \%$ to $40 \%$. To reach the same concentration of oxygen in flue gas during oxyfuel combustion, the excess of oxygen is in just units of percent.

\section{Methodology FOR STOICHIOMETRIC CALCULATIONS}

Stoichiometric calculations are volumetric calculations. They are used to determine the amount of oxidant required to burn a unit amount of fuel, and to determine the volume of the flue gases that arise. Stoichiometric calculations are based on chemical reaction equations and the balance of the amount of substance. In general, we consider two basic models here - a complete combustion model, and an incomplete combustion model. The complete combustion model considers complete combustion of all combustible substances. The incomplete combustion model can calculate with only partial fuel burn out and with unburned carbon formation. Although the incomplete combustion model is more appropriate, the complete combustion is used in most model technical applications uses, and it is also used here [6].

Table 2 contains all equations that are needed for computing all volume streams in the boiler. The volumes are stated in standard cubic meters per kilogram of fuel. 


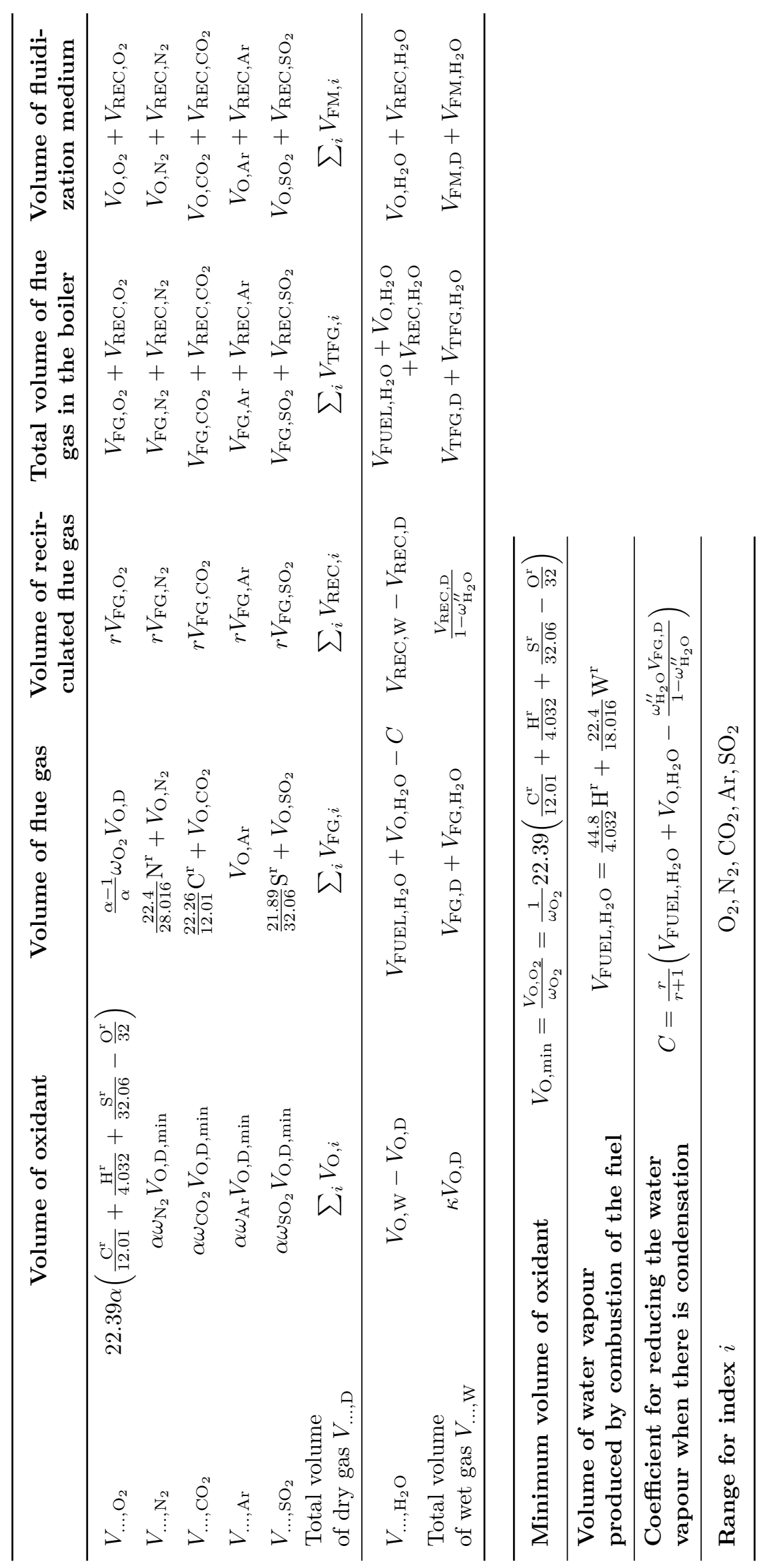

TABLE 2. List of equations for calculating the volume flows in the boiler. 


\begin{tabular}{lcccccc}
\hline $\mathrm{C}^{\mathrm{r}}[\%]$ & $\mathrm{H}^{\mathrm{r}}[\%]$ & $\mathrm{N}^{\mathrm{r}}[\%]$ & $\mathrm{S}^{\mathrm{r} *}[\%]$ & $\mathrm{A}^{\mathrm{r}}[\%]$ & $\mathrm{W}^{\mathrm{r}}[\%]$ & $\mathrm{Q}_{\mathrm{i}}^{\mathrm{r}}[\mathrm{MJ} / \mathrm{kg}]$ \\
\hline 39.05 & 3.5 & 0.51 & 0.65 & 15.23 & 28.5 & 16.9 \\
\hline * combustible sulphur & & &
\end{tabular}

TABle 3. Proximate and ultimate analysis of the coal.

\begin{tabular}{ccc}
\hline Excess of air & Recirculation coefficient $r$ & Temperature of the recirculated flue gas \\
\hline 1.4 & 0.3 & $120^{\circ} \mathrm{C}$ \\
\hline
\end{tabular}

TABLE 4. Combustion properties of the reference state.

\begin{tabular}{cccc}
\hline Mean diameter $[\mathrm{mm}]$ & Bulk density $[\mathrm{kg} / \mathrm{m} 3]$ & Density $[\mathrm{kg} / \mathrm{m} 3]$ & Sphericity $[-]$ \\
\hline 0.5 & 790 & 2195 & 0.75 \\
\hline
\end{tabular}

TABLE 5. Characteristics of the fluidized bed particles (coal ash).

\subsection{VOLUME OF OXIDANT}

The key step in stoichiometric calculations is to make a proper calculation of the concentrations of the substances in the oxidant. In this sense, the term oxidant refers to the air, the oxygen or the mixture of air and oxygen in the case of enriched oxygen combustion, as opposed to the volume of fluidization medium, which expresses the mixture of oxidant and recirculated flue gas (see Fig. 1). Table 1 shows the concentrations of the substances for various oxidants. Oxygen 1 denotes $100 \%$ pure oxygen, and is the value used for the calculations. In practice, it is assumed that some economical optimum of oxygen purity will be used. A value of $95 \%$ is usually quoted [1]. This is denoted as oxidant Oxygen 2. Table 1 also shows the concentrations for two types of oxygen-enriched air: Air+oxy 30 and Air+oxy 50, where the numbers correspond to the oxygen concentrations. The concentration of water vapour in air corresponds to $70 \%$ relative moisture at $20^{\circ} \mathrm{C}$.

First, the minimum volume of oxygen needed for complete combustion is calculated (Tab. 2). The excess of oxidant is defined as the ratio of the real volume of oxidant used for combustion and the minimum volume of oxidant:

$$
\alpha=\frac{V_{\mathrm{O}, \mathrm{W}}}{V_{\mathrm{O}, \mathrm{W}, \min }}=\frac{V_{\mathrm{D}, \mathrm{W}}}{V_{\mathrm{D}, \mathrm{W}, \mathrm{min}}} .
$$

To correctly determine the flow properties of the fluidization medium, it is necessary to know the composition and the concentration of the individual components. The fluidization medium comprises the volume of recirculated flue gas and the volume of oxidant (see Tab. 2).

\subsection{VOLUME OF THE FLUIDIZATION MEDIUM}

The volume of the fluidization medium is defined as the mixture of oxidant and recirculated flue gas. This stream depends mainly on the recirculation coefficient, defined by (2). The volume concentration of oxygen must usually be higher than $21 \%$ for oxy-combustion (typically about $30 \%$ ), in order to reach the same conditions as during air combustion. The calculated concentrations of the fluidized medium components are stated in Tab. 6 and Fig. 3 .

\subsection{Volume of Flue GAS AND total VOLUME OF FLUE GAS}

The volume of flue gas is given by the sum of the components that are formed during combustion $\left(\mathrm{CO}_{2}\right.$, $\mathrm{SO}_{2}, \mathrm{~N}_{2}$ from the fuel, $\left.\mathrm{H}_{2} \mathrm{O}\right)$ and the components that are contained in the oxidant but do not participate in the combustion process (excess of $\mathrm{O}_{2}, \mathrm{~N}_{2}, \mathrm{Ar}, \mathrm{H}_{2} \mathrm{O}$ from the air humidity).

The volume of water vapour in the flue gas is influenced by the potential condensation of water vapour in the recirculated flue gas, which will be explained below. This reduction is expressed by coefficient $C$ (Tab. 2). If there is no condensation of water vapour, coefficient $C$ equals 0 .

Total volume of flue gas is the real volume that is released from the boiler (see Fig. 1). It is the sum of the recirculated flue gas and the flue gas that arises from the oxidant. This stream passes through the boiler, and is the main heat carrier.

\subsection{Volume OF RECIRCULATED FLUE GAS}

Flue gas recirculation (FGR) is a very important aspect of combustion in fluidized bed boilers. Air combustion uses FGR to control the temperature of the fluidized bed and to ensure proper fluidization. In the case of oxyfuel combustion, it is the key approach for reducing the temperature in the combustion chamber and for keeping the necessary amount of fluidization medium flow. FGR is extracted after all heat exchanging parts of the boiler. The amount of FGR is expressed using a proportional recirculation coefficient $\mathrm{r}[-]$, which is defined in this work as the ratio of the volume of the recirculated flue gas to the volume of the residual flue gas leaving the combustor:

$$
r=\frac{V_{\mathrm{REC}, \mathrm{W}}}{V_{\mathrm{FG}, \mathrm{W}}} .
$$




\begin{tabular}{lccc}
\hline & Air & $\mathrm{OXY}_{1}$ & $\mathrm{OXY}_{2}$ \\
\hline Total volume of oxidant $V_{\mathrm{O}, \mathrm{D}}\left(\mathrm{m}_{\mathrm{n}}^{3} / \mathrm{kg}_{\text {fuel }}\right)$ & 5.61 & 0.89 & 0.89 \\
Volume of flue gas $V_{\mathrm{FG}, \mathrm{W}}\left(\mathrm{m}_{\mathrm{n}}^{3} / \mathrm{kg}_{\text {fuel }}\right)$ & 6.33 & 1.52 & 1.52 \\
Oxidant excess $\alpha(-)$ & 1.4 & 1.06 & 1.06 \\
Recirculation coefficient $r(-)$ & 0.3 & 3.24 & 4.41 \\
Total volume of flue gas $V_{\mathrm{TFG}, \mathrm{W}}\left(\mathrm{m}_{\mathrm{n}}^{3} / \mathrm{kg}_{\text {fuel }}\right)$ & 8.23 & 6.45 & 8.23 \\
Total volume of fluidization medium $V_{\mathrm{FM}, \mathrm{W}}\left(\mathrm{m}_{\mathrm{n}}^{3} / \mathrm{kg}_{\text {fuel }}\right)$ & 7.6 & 5.81 & 7.6 \\
$\mathrm{O}_{2} / \mathrm{CO}_{2}$ ratio $($ dry) in fluidization medium $(-)$ & - & $30 / 70$ & $25 / 75$ \\
$\mathrm{SO}_{2}$ concentration in dry flue gas $(\mathrm{ppm})$ & 800 & 5800 & 5800 \\
Adiabatic temperature of the flame $T_{\mathrm{AD}}\left({ }^{\circ} \mathrm{C}\right)$ & 1316 & 1316 & 1082 \\
Minimum fluidization velocity $u_{\mathrm{fm}}^{*}(\mathrm{~m} / \mathrm{s})$ & 0.33 & 0.32 & 0.32 \\
Minimum terminal velocity $u_{\mathrm{t}}^{*}(\mathrm{~m} / \mathrm{s})$ & 2.91 & 2.84 & 2.84 \\
\hline The minimum fluidization velocity and the minimum terminal velocity were
\end{tabular}

* The minimum fluidization velocity and the minimum terminal velocity were calculated from the composition of the fluidization medium at the temperatures of the fluidized bed $\left(850^{\circ} \mathrm{C}\right)$.

TABLE 6. Results of the calculations.

When the recirculated flue gas is cooled down below of the dew point temperature (e.g. because of the low operation temperature of the FGR fan), the water vapour begins to condense. The computation methodology given in Tab. 2 includes the reduction in water vapour due to condensation.

If we introduce the simplifying assumption of an ideal gas and the assumption that the absolute gas pressure is equal to $0.1 \mathrm{MPa}$, we can say that the water vapour concentration is equal to the partial pressure of the water vapour. The maximum water vapour concentration will therefore be equal to the saturation pressure for a given temperature.

If the gas temperature in the system does not fall below the dew point temperature (for the oxyfuel mode below approx. $80^{\circ} \mathrm{C}$ ), there is no condensation and the volume of the water vapour in the recirculated flue gas is calculated using the same relation as in the calculation for other compounds:

$$
V_{\mathrm{REC}, \mathrm{H}_{2} \mathrm{O}}=r V_{\mathrm{FG}, \mathrm{H}_{2} \mathrm{O}}
$$

The total volume of wet recirculated flue gas is then:

$$
V_{\mathrm{REC}, \mathrm{W}}=V_{\mathrm{REC}, \mathrm{D}}+V_{\mathrm{REC}, \mathrm{H}_{2} \mathrm{O}}
$$

\section{Results AND DisCussion}

The oxyfuel combustion in a bubbling fluidized bed (BFB) was verified using theoretical complete combustion methodology introduced above. Verifying the hydrodynamic characteristics of the BFB involves computing the minimum fluidization velocity, using the Ergun equation and the terminal velocity of the particles [7]. The fuel used for the computations is lignite coal. A proximate and ultimate analysis of the fuel is presented in Tab. 3 .

Computations were first performed for the reference state of combustion using air. The combustion properties of the reference state are summarized in Tab. 4. Table 5 summarizes the characteristics of the fluidized bed particles (coal ash).
It has already been verified that these conditions account for the real operation conditions for two experimental BFB boilers (one 0.5 MW [1] and one $25 \mathrm{~kW}[12]$ ).

Calculations were then made for oxyfuel combustion. The main aim was to find an oxyfuel mode for which the temperature and flow ratios would be similar to the values for air combustion, meaning that it is also applicable for BFB technology. Because it is difficult to determine theoretically the exact temperature in the fluidized bed, the adiabatic combustion temperature was chosen as one of the correlation parameters. It was derived from the total heat released in the furnace. This alternative will be denoted as $\mathrm{OXY}_{1}$. The second approach uses a comparison based on the same flow of the fluidizing medium, which would ensure sufficient fluidization of the fluidized bed (which will be denoted as $\mathrm{OXY}_{2}$ ). All the alternatives are summarized in Tab. 6.

Figures 2 and 3 show the concentrations of the main components in the flue gas and in the fluidization medium, respectively. The concentrations are calculated in wet flue gas.

On the basis of Tab. 4, Fig. 2 and Fig. 3 , the following statements can be made:

(1.) The volume of oxidant is reduced by more than $84 \%$ for oxyfuel combustion. It is therefore impossible to ensure fluidization when only oxygen is used.

(2.) Oxyfuel combustion produces about a $76 \%$ lower amount of flue gas. Flue gas absorbs most of the heat that is released during combustion. This low volume of flue gas would absorb only a minor fraction of the heat that is released, and the adiabatic flame temperature without the use of recirculation would be as high as $3700{ }^{\circ} \mathrm{C}$. It is therefore impossible to operate the oxyfuel BFBC (or any oxyfuel boiler) without using a high degree of flue gas recirculation. Flue gas recirculation is also required in order to keep a sufficient volume of the fluidization medium. 


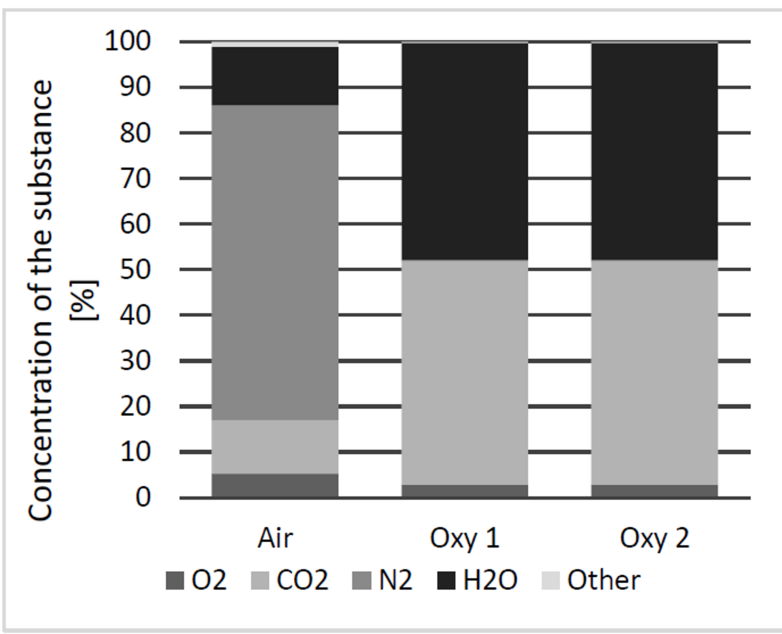

Figure 2. Concentration of the main substances in the flue gas.

(3.) Although the fluidization medium has a different share of components, it has only a marginal effect on the computation of the minimum fluidization velocity. The effect on the terminal velocity is slightly greater, but is still only in units of percent.

(4.) It is impossible to achieve equal oxy-combustion and air-combustion regimes in terms of simultaneously having the same thermodynamic and hydrodynamic parameters. Two boundary limit cases were calculated. $\mathrm{OXY}_{1}$ mode has the same adiabatic temperature of the flame, but the volume of the fluidization medium is about $24 \%$ lower than the volume of the fluidization medium for air. To ensure a well-developed BFB, it is recommended to use at least twice the minimum fluidization velocity. If a larger amount of recirculated flue gas is used, the same volume of the fluidization medium can be ensured. However, this lowers the combustion temperature. This could lead, e.g., to lower desulphurization or to increased carbon monoxide emissions.

\section{Conclusions}

A universal methodology for stoichiometric calculations has been developed for the theoretical verification of oxyfuel combustion in BFB. The methodology is summarized in Tab. 2. The input parameters are the concentrations of the substances in the oxidant medium. This methodology allows us to calculate the flow of all streams in the boiler for combustion with air, with oxygen-enriched air, and with pure oxyfuel. According to the calculations for the two different oxyfuel modes and for the air combustion mode presented here, the following conclusions can be drawn:

(1.) There is an $84 \%$ reduction of in the oxidant volume in comparison with air combustion.

(2.) The volume of flue gas is more than $76 \%$ lower than for air combustion.

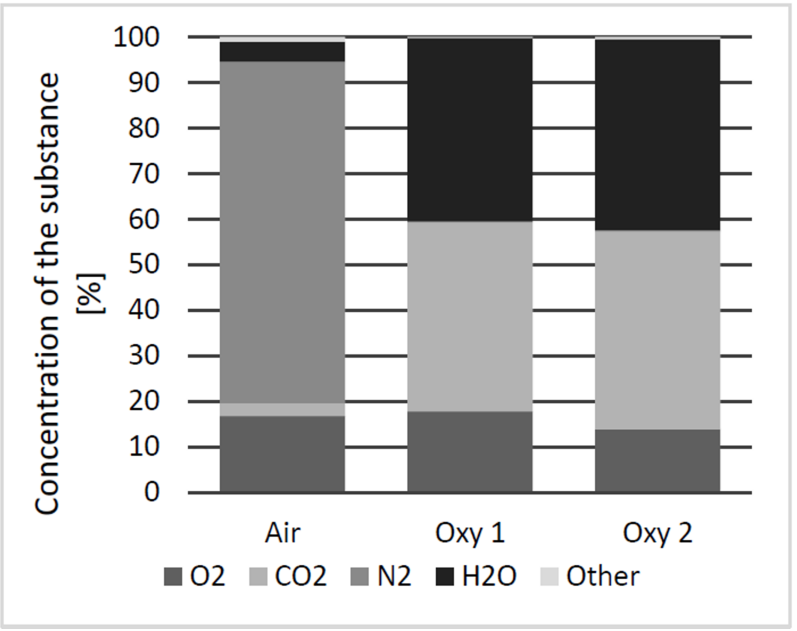

Figure 3. Concentration of the main substances in the fluidization medium.

(3.) A high degree of flue gas recirculation is therefore required.

(4.) Different compositions of the oxyfuel fluidization medium and air have only a marginal effect on the minimum fluidization and terminal velocities.

(5.) It is impossible simultaneously to reach appropriate temperature volume flow ratios. The most typical mode in practical applications is a mode between $\mathrm{OXY}_{1}$ and $\mathrm{OXY}_{2}$ cases. It is always important to ensure proper fluidization for BFBC. A lower combustion temperature can be compensated by a higher thermal load.

\section{LIST OF SYMBOLS}

$C$ Coefficient for reducing water vapour when there is condensation $\left[\mathrm{m}_{\mathrm{n}}^{3} / \mathrm{kg}_{\text {fuel }}\right]$

$r \quad$ Recirculation coefficient $[-]$

$V_{\mathrm{FG}}$ Volume flow of flue gas $\left[\mathrm{m}_{\mathrm{n}}^{3} / \mathrm{kg}_{\text {fuel }}\right]$

$V_{\mathrm{FM}}$ Volume flow of fluidization medium $\left[\mathrm{m}_{\mathrm{n}}^{3} / \mathrm{kg}_{\text {fuel }}\right]$

$V_{\mathrm{O}} \quad$ Volume flow of oxidant $\left[\mathrm{m}_{\mathrm{n}}^{3} / \mathrm{kg}_{\text {fuel }}\right]$

$V_{\mathrm{REC}}$ Volume flow of recirculated flue gas $\left[\mathrm{m}_{\mathrm{n}}^{3} / \mathrm{kg}_{\text {fuel }}\right]$

$V_{\text {TFG }}$ Volume flow of total flue gas $\left[\mathrm{m}_{\mathrm{n}}^{3} / \mathrm{kg}_{\text {fuel }}\right]$

$\alpha$ Excess of oxidant [-]

$\omega_{i}$ Concentration of substance i $\left[\mathrm{m}^{3} / \mathrm{m}^{3}\right]$

$\omega_{\mathrm{H}_{2} \mathrm{O}}^{\prime \prime}$ Saturated concentration of the water vapour $\left[\mathrm{m}^{3} / \mathrm{m}^{3}\right]$

SUBSCRIPTS

D Dry state

min Minimal amount

W Wet state

\section{ACKNOWLEDGEMENTS}

This work was supported by the Grant Agency of the Czech Technical University in Prague, in the framework of grant No. SGS13/181/OHK2/3T/12, and by project TA3020312 Research of Oxyfuel Combustion in a Bubbling Fluidized Bed for CCS Technologies. We gratefully acknowledge support from these grants. 


\section{REFERENCES}

[1] WALL, T. et al. An overview on oxyfuel coal combustion - State of the art research and technology development. Chemical Engineering Research and Design. 2009, vol. 87, p. 1003-1016.

[2] BUHRE, B. J. P. et al. Oxy-fuel combustion technology for coal-fired power generation. Progress in Energy and Combustion Science. 2005, vol. 31, p. 283-307.

[3] The Schwarze Pumpe pilot plant. In: Vattenfall (online). http:

//www .vattenfall.com/en/ccs/schwarze-pumpe.htm [2013-11-14].

[4] The Callide Oxyfuel Project. In: Global CCS Institute (online). http://www.globalccsinstitute.com/ insights/authors/dennisvanpuyvelde/2013/02/13/ callide-oxyfuel-project [2013-11-14].

[5] LUPION, M. I. et al. 30 MWth CUIDEN Oxy-CFB Boiler - First experiences. Energy Procedia. 2013, vol. 37, p. $6179-6188$

[6] LUO, W. et al. Exergy-based control strategy selection for flue gas recycle in oxy-fuel combustion plant. Fuel. 2015, vol. 161, p. 87-96
[7] LASEK, J. et al. Analysis of the transition time from air to oxy-combustion. Chemical and Process Engineering. 2015, vol. 36, p. 113-120

[8] CHEN, L. et al. Oxy-fuel combustion of pulverized coal: Characterization, fundamentals, stabilization and CFD modeling. Progress in Energy and Combustion Science. 2012, vol. 38, p. 156-214

[9] DLOUHÝ, T. Výpočty kotlů a spalinových výměníku․ Praha: Nakladatelství ČVUT, 2007. ISBN 978-80-01-03757-7.

[10] KUNII, D. and O. LEVENSPIEL. Fluidization Engineering, Second Edition. Stoneham: Butterworth Heinemann, 1991. ISBN 0-409-90233-0.

[11] SKOPEC, P. et al. NOx emissions from bubbling fluidized bed combustion of lignite coal. Acta Polytechnica. 2015, vol. 55, p. 275-281

[12] SKOPEC, P. et al. Studium problematiky využití fluidní vrstvy pro spalování biomasy a alternativních paliv. In Sborník přednášek z konference Energie z biomasy XIV. Brno: VUT v Brně, Fakulta strojního inženýrství, 2013, s. 69-73. ISBN 978-80-214-4775-2 